\title{
Study on Cultivation of Nonverbal Communicative Competence: A Cross-cultural Perspective
}

\author{
Hongling Luo \\ Overseas Education College \\ Xiamen University \\ Xiamen, China \\ School of Foreign Languages \\ Guizhou Normal University \\ Guiyang, China
}

\begin{abstract}
Nonverbal communication, together with language communication, accomplishes communicative tasks, and complementing each other. For the cross-cultural differences of nonverbal communication, L2 learners are prone to make social and pragmatic errors by misusing the nonverbal communicative means in the target language environment. It is argued that the cultivation of $L 2$ learner's nonverbal communicative competence should follow the overall development of the communicative competence, and language teachers should carry out a meaningful holistic language teaching activities and teaching mode so as to motivate and cultivate learners' potential integrative competence by the means of utilizing the affordances of the target language environment and mobilizing their multisensory channels.
\end{abstract}

Keywords-cross-culture; nonverbal communicative competence; affordance; mutisensory interaction

\section{INTRODUCTION}

Linguisitc communicative competence is a kind of comprehensive ability, with which learners can achieve effective communication according to different communicators, communicative purposes and social situations, combining language ability and nonverbal ability [1]. However, most of the linguistic competence research in the traditional second language acquisition field only emphasizes linguistic competence, and rarely incorporates the nonverbal ability into the study scope. From the perspective of sociolinguistics, the typical types of speech in a certain social and cultural environment are not limited to linguistic signs, but also include nonverbal symbols such as gestures, facial expressions and symbols such as icons and figures, forming multimodal information in the process of exchange. Shanker employs the dance metaphor to show vividly that sound, melody, facial expressions provide a basis for mutual understanding and multimodal coordination in peopole's social interaction, promoting learners' linguisitic ability and other nonverbal ability, such as observation, insight, imitation, understanding, reflection and empathy [2]. Therefore, the development of linguistic communicative competence can not be separated from other nonverbal ability, and the discussion of linguistic communicative competence can not be restricted to the linguistic level, but also the non-linguistic level. Language teachers should improve the learners' language comprehensive ability by improving learners' nonverbal communicative consciousness so as to avoid misunderstanding in cross-cultural communication.

This paper explores the nonverbal communication competence and its development of L2 learners from crosscultural perspectives. It first discusses the types and functions of nonverbal communication. Then, it discusses the importance of nonverbal symbols in cross-cultural communication, with an questionnaire on Thai students in China as an example about how they conducts in everyday communication. Finally, the paper puts forward the teaching principles and strategies of cultivating L2 learners' nonverbal communicative competence based on the holistic mode of language communicative competence.

\section{TYPOLOGY AND FUNCTION OF NONVERBAL COMMUICATION}

Nonverbal communication refers to any communicative means in addition to language forms that convey information to each other in communication, including eye contact, facial expressions, kinesics, gestures, proxemics, paralanguage, etc. Qian Guanlian looks nonverbal communicative means as a bundle of symbols that attach to the communicators, helping participate and coordinate in interpersonal communication. Those means themselves are characterized by multimodality with the symbolic nature [3]. Leathers regard nonverbal communication as a communicative system that contains a set of interacting subsystems. And the nonverbal communicative system interacts with the verbal communicative system, thus constituting the human communication system [4]. Specifically, nonverbal communicative system consists of visual communicative system, auditory communicative system and invisible communicative system. The visual communicative system includes kinesics, proxemics, and communicationrelated items; invisible communicative system includes tactile, olfactory, time and other subsystems. These subsystems have influence on each other with the development of communication.

Based on cross-cultural communication and foreign language teaching research, Bi Jiwan [5] classifies nonverbal 
communicative system into four categories, namely, body language, paralanguage, environment language and object language. Body language refers to the basic gestures and body movements; paralanguage includes silence, a variety of nonsemantic sound and nonverbal turn-taking marks in the conversation; environment language refers to temporal and spatial information in the context; and object language refers to any objects that provide information in communication, even including one's appearance and dressing style.

The traditional linguistic communication research regards nonverbal communication as an adjunct to verbal communication. However, in the process of real social interaction, nonverbal communication and verbal communication each bear a certain communicative function, the two complement each other to complete the communication task and achieve the ultimate communicative purposes. In the same way, nonverbal communication plays the following roles in communication: repeating, supplementing, replacing, adjusting, contradicting and emphasizing [6]. In addition, nonverbal communication has the following characteristics compared with verbal communication: first, the amount of transmitted information is greater than the amount of verbal communication. Mehrabian argues that $38 \%$ of communicative information comes from speech mode, $7 \%$ from the words, and the remaining $55 \%$ is due to gestures, facial expressions, and other body movements [7]. Schelbert's study finds that in faceto-face intercultural communication, speech delivers $35 \%$ of the information, while the other $65 \%$ of the information is communicated through nonverbal performance. Further, 82\% of the teaching information goes through the teacher's nonverbal instruction and only $18 \%$ of the information is achieved through speech in classroom teaching [8]. Second, nonverbal communicative information is multimodal. In the real communicative context, the communicators mobilize all the senses and all means of performance practices for immediate, dynamic, multimodal and multifaceted information exchange [9]. For example, nonverbal information, such as facial expressions, gestures, body movements, postures, coughs, dressing, hairstyle, smells, verbal stress, pause, rhythm, and even silence in communication can simultaneously convey a variety of information from various aspects to the communicators. These nonverbal communicative information through human sensory multichannels indirectly or implicitly convey the speaker's true communication intentions and inner feelings to the other side. In short, effective communication is the result of the interaction and cooperation between verbal and nonverbal parts of communication.

\section{CUltural DifFERENCES IN NONVERBAL COMMU- NICATION}

Nonverbal communicative means and symbols have social and cultural norms, which require the communicators to follow so as to adjust their interaction in order to avoid cross-cultural communication conflicts and misunderstandings. The existing cross-cultural communication researches show that people have high tolerance for the erros of pronunciation, grammar, vocabulary in communication, whereas they have a very high cultural sensitivity for pragmatic errors, including the speaker's nonverbal pragmatic failures. This is because people tend to rely on their own cultural environment and cultural orientation to conduct themselves, gradually developing the specific communicative patterns and cultural system shared by the community group.

Hall [10] and Hofstede [11] observed the communicative behavior patterns of many different cultural groups in interpersonal communication in their respective studies. Their research findings were later refined into six dimensions that are suitable for a comparative study of all cultural typologies, namely: high/low context, monochronic/polychronic time system, individualism/collectivism, uncertainty avoidance, power distance, and masculinity/femininity. The cultural dimension theory also applies to cross-cultural nonverbal communication research.

High context is characterized by information placed in a communicative environment rather than stated explicitly. The low context emphasizes that any information must be expressed through language. Asian countries pertain to high context culture; while Europeans and Americans tend to low context culture. For facial expressions, for example, the Chinese people usually keep the countenance whenever they are happy or frustrated. In contrast, Europeans and Americans tend to express their emotions.

From the dimension of time, we can observe the different nonverbal means in cross-cultural communication. AngloAmerican countries are representatives of monochronic time system, for them, time planning and arrangement seldom change. The concept of punctuality and deadline is deeply rooted. In contrast, people from polychronic time system are relatively random and flexible to time arrangement, for example, Arabs can interrupt arbitrarily or rearrange any affairs that they are dealing with at hand.

From the perspective of individualism/collectivism, individualism emphasizes personal values and self-center; collectivism, on the other hand, emphasizes harmony and power. The public spaces convey this kind of preference. For example, American people will maintain a certain distance with each other to protect personal freedom and privacy; while the Asians are insensitive to the public spaces, and even take clossness as intimacy and friendness.

From the perspective of power distance, the members from high power distance attach much significance to interpersonal relationships, conducting themselves according to their social identities and status; in contrast, members from low power distance advocate an equal social power. People from Britain and the United States and other countries are more inclined to low power distance than Asians do. Therefor, nonverbally, the Chinese follow the traditional Chinese communicative etiquette when the younger talk to the elders, the former must bow to listen respectfully; and when passing things to the elders, they must raise themselves slightly, using both hands to show courtesy.

Finally, from the perspective of gender, masculinity emphasizes male-led social dominance with a clear division of social labor, while femininity emphasizes equality between men and women, without distinction of social labor by gender. For example, in the ancient China, where masculinity prevailed, 
"the three obediences and the four virtues" was a strict norm on women's conducts, such as their sitting, walking, talking, eye contact, dressing and so on.

\section{NONVERBAL COMMUNICATION RESEARCH IN THE FIELD OF SECOND LANGUAGE ACQUISITION}

In the 1970s, Hymes proposed the concept of communicative competence, which emphasize the ability to use language in actual situations [12]. The introduction of this theory brought a new perspective to the field of applied linguistics. Some researchers carried out their studies from the perspective of language acquisition, testing and teaching, developing Hymes' theory further. Among these studies, however, nonverbal communicative competence is mentioned explicitly by few, except in Canale \& Swain'model and CelceMurcia's communicative competence model. In the 1980s, Canale \& Swain introduced communicative competence into the field of second language acquisition, claiming that L2 communicative competence was composed of grammatical competence, sociolinguistic competence and strategic competence [13]. Among them, Strategic competence is an important development of Hymes' theory. Strategic competence refers to the ability to use verbal and nonverbal strategies to remediate interruption and enhance the communicative effect. It can be seen that Canale \& Swain' model regards nonverbal means as a compensatory function in communication. For example, when they have difficulty to communicate each other, the communicators can turn to some gestures and even role play for help. Celce-Murcia incorporates five components of communicative competence (socio-cultural, linguistic, discursive, interactive, and formulaic) from the perspective of second language acquisition and teaching. Celce-Murcia et al., classify nonverbal communicative elements into social and cultural competence and strategic competence. The nonverbal communicative elements in social and cultural competence are: body language, nonverbal turntaking marks, feedback behavior, emotional marks (facial expression), gesture, eye contact, space use, touch, paralanguage, silence, etc.; the nonverbal means in strategic competence refers to miming, gesturing and drawing [14].

It can be seen that the traditional communicative competence research puts too much emphasis on the language itself, while ignoring the multichannel information exchange in real communication context. With the further study of communicative competence, nonverbal communicative competence has been paid more and more attention. Some scholars make supplements from different perspectives. For example, researchers on discourse analysis believe that the study of communicative competence ignores the interaction and communicative performance in context, and contextual cues play an important role in constructing and understanding communicative meaning. Contextual cues can be verbal or nonverbal, such as gestures, facial expressions, body language and other nonverbal means, by which speakers can infer the communicative intention. Shu Dingfang argues that communicative competence embodies the overall quality of people, not only the ability to use language, but also the body, facial expressions and other nonverbal means to achieve communicative purposes [15]. Zheng Tongtao claims that language communication is a complex dynamic system that incorporates three subsystems: body, brain and environment. Those subsystems have an effect on each other and afford potential communicative information during the communicating process, which include a lot of key elements, such as verbal words, premises, body movements, tones, sound volume, facial expressions, public spaces, etc. A successful communication is achieved through verbal and nonverbal competence. Therefore, L2 communicative competence is a multi-channel product and the embodiment of the comprehensive ability of the human body, including linguistic competence, body movements and human sensory system [16].

However, in general, the current research on nonverbal communicative competence is a weaker link, lacking in systematic combing and researching. And there is little discussion on the effective application of nonverbal elements in communication, not mention the development of L2 learners' nonverbal communicative competence. It is the weakness that directly affects the effectiveness of the second language / foreign language teaching.

\section{A SURVEY OF L2 LEARNERS' NONVERBAL COMMUNICATIVE COMPETENCE}

In order to investigate nonverbal communicative competence of L2 learners of Chinese, we conducted a preliminary survey of 60 Thai students from Overseas Education College of Xiamen University. A total of 60 questionnaires were handed out and 49 were got replied effectively. The questions are designed by refering to Liu Songhao's pragmatic survey [17] partially, which involves the performance of gestures, facial expressions, paralanguages, power distance, time views in nonverbal communication. The questions are as "Table I" and "Table II".

TABLE I. A QUESTIONNAIRE ON NONVERBAL COMMUNICATION OF L2 LEARNERS OF CHINESE FROM THAILAND

\begin{tabular}{|l|l|}
\hline No. & \multicolumn{1}{c|}{ Questions } \\
\hline 1 & $\begin{array}{l}\text { You ask your friend that how many people in the classroom, your } \\
\text { friend makes a gesture by stretching out his thumb and forefinger } \\
\text { open, the other three fingers bent toward the palm. What does he } \\
\text { mean? }\end{array}$ \\
\hline 2 & $\begin{array}{l}\text { If a girl receives a compliment, she may keep her arms straight, and } \\
\text { cross in front of the body, while the face turned to the side with a } \\
\text { smile. How do you understand the body movement? }\end{array}$ \\
\hline 3 & $\begin{array}{l}\text { Keep the index fingers vertically on the middle of the closed lips, } \\
\text { letting out the sound"sh". What does the gesture mean? }\end{array}$ \\
\hline 4 & $\begin{array}{l}\text { What will you think when you see two adult men hand in hand } \\
\text { walking on the road? }\end{array}$ \\
\hline 5 & $\begin{array}{l}\text { What does the gesture mean by rubbing the side of your cheek with } \\
\text { the index finger, and keeping your lips curled down? }\end{array}$ \\
\hline 6 & What do you mean by pointing to your nose with a finger? \\
\hline 7 & What do you think if your friends touch your head? \\
\hline 8 & What will you do when you come across your elders? \\
\hline 9 & How do you walk with your elders? \\
\hline 10 & $\begin{array}{l}\text { When you ask someone to pass something, he or she pass it to you } \\
\text { with the left hand. What do you think of this? }\end{array}$ \\
\hline 11 & Do you wait in line when you wait for a bus? \\
\hline 12 & What do you think of being late? \\
\hline 13 & $\begin{array}{l}\text { Do you think it's normal to have lunch at two o'clock in the } \\
\text { afternoon? }\end{array}$ \\
\hline 14 & $\begin{array}{l}\text { What do you think if your friends visit your room without your } \\
\text { permission? }\end{array}$ \\
\hline 15 & Do you like perfume? \\
\hline
\end{tabular}


TABLE II. THE RESUlTS OF THE QUESTIONNAIRES

\begin{tabular}{|c|c|c|c|}
\hline \multirow{2}{*}{ No. } & \multicolumn{3}{|c|}{ The Options of Each Question } \\
\hline & $A(\%)$ & $B(\%)$ & $C(\%)$ \\
\hline 1 & Two $(0 \%)$ & Eight $(20.7 \%)$ & $\begin{array}{l}\text { No } \quad \text { such } \\
\text { gesture }(79.3 \%)\end{array}$ \\
\hline 2 & Thanks(24.1\%) & $\begin{array}{l}\text { The girl is very shy. } \\
(72.4 \%)\end{array}$ & $\begin{array}{l}\text { No such } \\
\text { gesture }(3.5 \%)\end{array}$ \\
\hline 3 & Make a joke( $31 \%)$ & Keep quiet(48.3\%) & $\begin{array}{l}\text { No } \quad \text { such } \\
\text { gesture }(20.7 \%)\end{array}$ \\
\hline 4 & $\begin{array}{l}\text { They are gay. } \\
(37.9 \%)\end{array}$ & $\begin{array}{l}\text { They are close } \\
\text { friends. }(44.8 \%)\end{array}$ & $\begin{array}{l}\text { I have no idea. } \\
(17.3 \%)\end{array}$ \\
\hline 5 & $\begin{array}{l}\text { It doesn't matter. } \\
(25 \%)\end{array}$ & $\begin{array}{l}\text { It is disgraceful. } \\
(25 \%)\end{array}$ & $\begin{array}{l}\text { No such } \\
\text { gesture }(50 \%)\end{array}$ \\
\hline 6 & I did. $(44.8 \%)$ & I'm sorry. (31\%) & $\begin{array}{l}\text { No } \quad \text { such } \\
\text { gesture }(24.2 \%)\end{array}$ \\
\hline 7 & He is rude. $(44.8 \%)$ & $\begin{array}{l}\mathrm{He} \text { is friendly. } \\
(55.2 \%)\end{array}$ & $\begin{array}{l}\text { I have no } \\
\text { idea. }(0 \%)\end{array}$ \\
\hline 8 & $\begin{array}{l}\text { Let the elders go first } \\
\text { by moving quickly } \\
\text { aside and hands } \\
\text { together }(27.6 \%)\end{array}$ & $\begin{array}{l}\text { Greet the elder and } \\
\text { go away. }(62.1 \%)\end{array}$ & $\begin{array}{l}\text { Look the other } \\
\text { way. }(10.3 \%)\end{array}$ \\
\hline 9 & $\begin{array}{l}\text { Walk with a certain } \\
\text { distance, the body } \\
\text { slightly } \\
(20.7 \%)\end{array}$ & $\begin{array}{l}\text { Walk close next to } \\
\text { him or her. }(41.4 \%)\end{array}$ & $\begin{array}{l}\text { Walk behind him } \\
\text { or her. }(37.9 \%)\end{array}$ \\
\hline 10 & $\begin{array}{l}\text { It isn't polite, he or } \\
\text { she should use the } \\
\text { right hand. }(3.4 \%)\end{array}$ & $\begin{array}{l}\text { It doesn't matter as } \\
\text { long as he or she } \\
\text { passes it to me. } \\
(72.4 \%)\end{array}$ & $\begin{array}{l}\text { He or she should } \\
\text { use the both } \\
\text { hands. }(24.2 \%)\end{array}$ \\
\hline 11 & $\begin{array}{l}\text { No, because they } \\
\text { don't line up. }(27.6 \%)\end{array}$ & Yes. $(44.8 \%)$ & $\begin{array}{l}\text { Let them go first. } \\
(27.6 \%)\end{array}$ \\
\hline 12 & It's normal. $(31 \%)$ & $\begin{array}{l}\text { No, it should be on } \\
\text { time. }(69 \%)\end{array}$ & $\begin{array}{l}\text { I have no idea. } \\
(0 \%)\end{array}$ \\
\hline 13 & It's normal. (37.9\%) & It's too late. $(62.1 \%)$ & $\begin{array}{l}\text { I have no } \\
\text { idea. }(0 \%)\end{array}$ \\
\hline 14 & $\begin{array}{l}\text { It's not polite. } \\
(35.1 \%)\end{array}$ & $\begin{array}{l}\text { It doesn't matter. } \\
(64.3 \%)\end{array}$ & $\begin{array}{l}\text { I have no idea. } \\
(0 \%)\end{array}$ \\
\hline 15 & Yes, I do. $(67.9 \%)$ & No, I don't. (32.1\%) & $\begin{array}{l}\text { I have no idea. } \\
(0 \%)\end{array}$ \\
\hline
\end{tabular}

According to the results, the Thai students made some nonverbal pragmatic errors in their cross-cutural communication with the Chinese. For example, questions 1, 3, 5 , and 6 examine the proper use of gestures in Chinese culture. While $79.3 \%, 20.7 \%, 50 \%$ and $24.2 \%$ of the students chose "no such gesture". Actually, those gestures are quite common in China. Question 7 examines the peroper use of body touch in Chinese culture. In Thailand, the head is the most sacred part of the body and nobody can touch it, while it is a gesture for friendness and love when the elders touch your head in Chinese culture. So $44.8 \%$ of Thai students chose option A "He is rude" Questions 8 and 9 examine the proper understanding of power distanc. The choice of most Thai students also reflects the unique cultural norms of Thais. If they encounter their elders on the road, the appropriate communicative behavior is to let the elders go first by moving quickly aside, hands together. When walking with the elders, they should walk behind them and keep a certain distance. Questions 4, 1 and 14 examine the proper use of public space. The answers of the Thai students show that Thais value their personal privacy far more than the Chinese. And Questions 12 and 13 examine their attitude toward time. As we can see from the results, part of students have a high degree of tolerance for being late, which is different from the Chinese. And question 15 shows that $67.9 \%$ of the students often use perfume, which is different from the traditional Chinese aesthetic views.

The survey not only confirms the existence of cultural differences in nonverbal communication behavior, but also shows that communicators can employ facial expressions, gestures and other nonverbal means to understand each other, even if the language used by the other communicator is beyond their understanding. It can improve the effectiveness of L2 communication by proper use of nonverbal means. On the contrary, the nonverbal communication errors are much more serious than grammatical mistakes. Therefore, the present communicative competence theory needs to include nonverbal communication factors as an important component in the research field, which can guide the comprehensive development of communicative competence of second language learners.

\section{DEVELOPMENT AND CULTIVATION OF L2 LEARNERS' NONVERBAL COMMUNICATIVE COMPETENCE}

As mentioned above, communicative competence is a kind of human comprehensive ability, which embodies the overall quality of a person, so we can not separate verbal and nonverbal competence in contextual communication. The communicative meaning derives from the combination of nonverbal symbols and linguistic symbols on both sides of the communicator. That's why we say the development of communicative competence is actually the interaction between L2 learners and native speakers in the target language environment, which means that the formation and development of communicative competence requires L2 learners to experience the real communicating process in social interaction, to summarize the speech features and nonverbal features in the context, and to abstract them into different contextual communicative patterns. With the continuous accumulation and exposure to more communicative patterns, learners' communicative competence will emerge from communicative activities so as to get access to the overall development of language communication capacity. With the continuous interaction between the learners and the environment, learner's communicative competence got developed further, which is a ecological cycle of developing process.

The law of the development language communicative competence requires us to follow the principle of holistic language activity in teaching, paying attention not only to learners' linguistic competence, but also to their nonverbal competence development, which is embodied in the following principles:

\section{A. Application of a Holistic Teaching Approach}

Communicative competence is not acquired by teaching, and teachers' role is to provide opportunities for learners to practice as much as they can by appling various teaching methods, such as the direct method, situational method and communicative approach, which focus on the real use of language, affording a real communicative environment where verbal and nonverbal means are necessary. Whereas, the audiolingual method, total physical response, audio-visual method, and even games, music and drama can be employed to 
motivate learners' sensory system, so that they can achieve the internalization of the competence of observation, listening, understanding, communicating and interacting, which is consistent with the law of language development.

\section{B. Taking Advantages of Various Affordances of Learning Environments}

The language environment here refers to the target language environment, specifically, including all the oral and written language materials that L2 leanrers can get access to, and the physical environment, such as classroom teaching, conversations between teachers and students and among peers, and also everyday communicative environment and acitivities, such as watching TV, shopping, reading newspapers [18]. Traditional communicative competence researach excludes the environmental factors mentioned above. With the development of cognitive psychology, the theory of offordance proposed by perceptual psychologist Gibson is introduced into the field of second language acquisition to explore the relationship between environment and language learning. Van Lier interprets this relationship as: the environment provides learners with the potential for a wide range of available physical and social resources, and learner's perception and reaction on these potentials determine the effectiveness of language learning. In general, different learners pick up different affordances, and the learners with a strong agency will perceive and capture more compare with others in the same environment [19].

In this sense, the development of learners' communicative competence has an important relationship with the interaction of language learning environment. In other words, the native speakers they talk with, the communicative patterns they master, and the information they capture and perceive have a great influence on the learner's communicative competence. Therefore, cultivating learners' communicative competence, in fact,is to provide learning environment as much as possible for the learners, and more importantly, to stimulate learners' perceptions of the environment. In classroom teaching environment, teachers can apply modern teaching technology, such as multimedia, audio and video resources, audio-visual materials to teach, presenting a real language learning environment. In addition, teachers should provide opportunities for learners to communicate each other, such as various contests and competitions, social practices, community services, group activities and so on. In face-to-face interaction, the native speakers can show L2 learners how to communicate with a wealth of nonverbal communicative skills. Through observation, imitation, reflection, L2 learners can easily apply to their own practice, so as to promote the comprehensive development of communicative competence.

\section{Motivating Learners' Multimodal Interaction}

The interface and channels of information exchange between human and environment include five sensory channels: visual, auditory, olfactory, tactile and gustatory means, which constitute the five modes or modules of information processing. Therefore, the interaction between human and environment is multimodal. Nelson's research suggests that multi-channel cognitive patterns help us to understand concept in a holistic and comprehensive approach, which can promote language learning [20]. Zhang Delu points out that although each mode is self-sufficient and can assume the task of transmitting information, but in real communication, the speaker can not only use one modal. Different communication situations require the speaker to cooperate with multi-channels, or complement a major modality to highlight the information that is important to communicate, so that interpersonal communication is accurate and effective [21].

Therefore, L2 teachers should fully mobilize the learner's multi-sensory channel to cooperate and interact each other, such as watching movies and television or other forms of exchanges in the specific context of communication. Such mutimodal interaction integrating text, image, audio and video, not only provides a real communicative context for L2 learners, but help them perceive information input in a multimodal way. In addition, teachers should also fully mobilize the learner's multi-sensory channels to imitate native speakers' communicative performance. Imitation in language learning, especially in the target language environment, can help learners assimilate themselves and reestablish their self-identity in the target language environment, so that their communicative practice is more consistent with the target language social culture and value.

\section{CONCLUSION}

As an important part of cross-cultural communication, nonverbal communication plays a vital role since the human communication begins. With the globalization and development of science and technology, nonverbal communication will play an increasingly important role in communication. For the second language/foreign language teaching, our ultimate goal is not only to enable L2 learners to master linguistic grammars, but to cultivate all-round communicative competence, verbal and nonverbal, so that L2 learners can complete any communicative tasks in the real social interaction. The training principles of nonverbal communicative competence in this paper is based on the actual practice in social interaction, which is in line with the needs of L2 learners' cross-cultural communication and the law of a comprehensive development of communicative competence.

\section{REFERENCES}

[1] Tongtao Zheng, Overseas Education for 60 Years. Fujian: Xiamen University Press, 2016.

[2] S. Shanker and B. King, "The emergence of a new paradigm in ape language research", Behavioral and Brain Sciences, Vol. 25, No. 5, 2002, pp. 605-626.

[3] Guanlian Qian, Pragmatics in Chinese Culture: Speechology in Humanistic Networks. Beijing: Qinghua University Press, 1997.

[4] D. G. Leathers, Successful Nonverbal Communication: Principles and Applications. Boston: Allyn and Bacon, 2007.

[5] Jiwan Bi, Intercutural Nonverbal Communication. Beijing: Foreign Language Teaching and Research Press, 2012.

[6] D. Shulman and R. Penman, "Non-verbal communication,"in Contact: Human Communication and Its History, R. Williams, Eds. London: Thames and Hudson, 1981, PP.52-70. 
[7] A. Mehrabian and S. R. Ferris, "Inference of attitudes from nonverbal communication in two channels", Journal of Consulting Psychology, No. 3, 1967, pp. 248-252.

[8] L. Schelbert, "Pathways of human understanding: An inquiry into western and North American Indian world-view structures", American Indian culture and research journal, Vol. 27, No. 1, 2003, pp. 61-75.

[9] Haikuo Yu, A Performative Approach to Communicative Competence in Teaching Chinese as a Second Language. Doctoral Dissertation of Xiamen University, 2013.

[10] E. T. Hall, The Hidden Dimension of Time. New York: Doubleday, 1969.

[11] G. Hofstede, Culture's Consequence: International Differences in Work-related Values. Newbury: Sage, 1980.

[12] D. H. Hymes, "On communicative competence," in Sociolinguistics: Selected Readings, J. B. Pride and J. Holmes, Eds., Harmondsworth: Penguin, 1972, pp. 269-293.

[13] M. Canale and M. Swain, "Theoretical bases of communicative approaches to second language teaching and testing", Applied Linguistics, Vol. 1, No 1, 1980, pp. 1-47.

[14] M. Celce-Murcia, "Rethinking the role of communicative competence in language teaching," in Intercultural Language Use and Language Learning, E. A. Soler and P. S. Jorda, Eds. Dordrent: Springer, 2007, PP.41-57.

[15] Dingfang Shu, "On foreign language communicative competence and its cultivation", Foreign Language Research, Vol. 68, No 3, PP. 9-14, June 1993 (in Chinese).

[16] Tongtao Zheng, "The study of complex dynamic system in teaching Chinese as a foreign language", Journal of International Chinese Studies, Vol. 5, No 2, PP. 1-16, July 2014 (in Chinese).

[17] Songhao Liu and Junjie Tian, "An analysis of an investigation of CSL leanrers'pragmatic competence", Applied Linguistics, Vol. 29, No 1, PP. 85-92, April 1999 (in Chinese).

[18] Manchun Dai and Yunnan Xiao, "The types and functions of language environment", Journal of Social Science of Hunan University, Vol. 9, No. 2, PP. 104-109, April 1995 (in Chinese).

[19] L. Van Lier, The Ecology and Semiotics of Language Learning: A Sociocultural Perspective. New York: Kluwer Academic Publishers, 2004.

[20] M. E. Nelson, "Mode, meaning, and synesthesia in multimedia L2 writing", Language Learning \& Technology, Vol. 10, No. 2, PP. 56-76, 2006.

[21] Delu Zhang, "Application of multimodal discourse and mulitmedia modern media technology in foreign language teaching", Foreign Language Education, Vol. 30, No. 4, PP. 15-20, July 2009 (in Chinese). 